\title{
Prevalence and prognosis of electrocardiographic findings in middle-aged men
}

\author{
G. ROSE, P. J. BAXTER, D. D. REID,1 AND P. MCCARTNEY \\ From the Department of Medical Statistics and Epidemiology, London School of Hygiene and \\ Tropical Medicine, London
}

SUMMARY A screening examination including an electrocardiogram (limb leads only) coded by the Minnesota Code, using rigorous quality control was done on 18403 male civil servants aged 40 to 64 . The association of the findings with coronary heart disease has been tested in relation to age trends, symptomatic history, and coronary heart disease mortality rates in the ensuing five years. The results $\mathscr{G}_{\circ}$ were positive for $Q$ waves, left axis deviation, ST depression, and $T$ wave changes (including minor $\mathrm{T}$ 을 wave items as an isolated finding), ventricular conduction defects, and atrial fibrillation;but theywere generally unimpressive for increased $\mathrm{R}$ amplitude and for lengthening or shortening of the PR interval, $\subseteq$ QT interval duration, premature beats, and extremes of heart rate.

The prognosis of specific electrocardiographic findings discovered at screening is quite different from $\vec{\varphi}$ when they arise in clinical practice. Among the 6 per cent of men in this study with patterns suggesting $\infty$ ischaemia, the subsequent coronary heart disease mortality was little more than 1 per cent per year; and among those who were symptom free it was even less.

Until recently the electrocardiogram was used largely for the purpose of clinical diagnosis, and in this way doctors have become familiar with the significance of findings as they occur in sick patients. Increasingly, however, the electrocardiogram is also being recorded in apparently healthy people in order to assess occupational fitness or for other screening service, or else in the course of epidemiological surveys. This requires reassessment and reinterpretation of electrocardiographic findings as they arise in this different setting. Previous studies of this kind have been from other countries (Higgins et al., 1965; Kannel et al., 1969; Blackburn et al., 1970), in old people (Campbell et al., 1974; Caird et al., 1974), or based on small numbers or incompletely defined criteria. We report here the results of a prevalence survey with five-year mortality follow-up of the electrocardiographic findings classified according to the Minnesota Code in a large group of middle-aged British men currently employed as civil servants (Reid et al., 1974; Rose et al., 1977b).

\section{Subjects and methods}

The initial examination was attended by 18403 men aged 40 to 64 . In over 99 per cent of cases it

${ }^{1}$ Professor Reid died just before the manuscript was released for publication.

Received for publication 24 May 1977 was possible to identify and flag the man's record in the National Health Service Central Register and $\stackrel{\varnothing}{\complement}$ this provided a virtually complete mortality follow- $\overrightarrow{\vec{B}}$ up. In the 5 years after examination 657 men died. 3 The underlying causes of death were coded by the Registrar General's staff, 277 being assigned to coronary heart disease (ICD 410-414).

Before attending for examination the men were asked to complete a self-administered version of the London School of Hygiene chest pain questionnaire 3 (Rose et al., 1977a). A resting electrocardiogram was recorded on each man, using a 3-channel Mingograf machine. The recording comprised the 0 6 limb leads only: omission of chest leads was a regretted simplification necessary because of the large $\frac{T}{0}$ number of subjects involved and because each man was available for only a short time. This did not $O$ result in any important loss of information on axis, $N$ rhythm, or conduction disturbances, but right $\mathrm{N}_{\mathrm{N}}$ bundle-branch block and intraventricular con- 0 duction defect could not be distinguished from one another and have, therefore, been classified to- $\frac{C}{\Phi}$ gether. A comparison was made in an earlier study $\stackrel{?}{?}$ of the yield of codable $Q / Q S, S T$ segment, and $T_{T}$ wave findings in 6 and 12 lead electrocardiograms, $\vec{\circ}$ and it was shown that a 6 lead tracing identified $\stackrel{\odot}{\odot}$ about 75 per cent of the individuals who had such $\mathbb{\mathbb { D }}$ findings in the full 12 lead record. This conclusion $\frac{}{\sigma}$ has recently been corroborated by Evans and Tunbridge (1976). 
The technicians were instructed to record 5 technically adequate complexes in eachlead, of which the middle 3 were later analysed according to the Minnesota Code (Rose and Blackburn, 1968). Most of the coding was done by technicians, who are generally more suited than doctors to this repetitive application of rigid and elaborate rules for identifying, measuring, and coding the various components of the tracing (Rose, 1965). All coders had first completed a detailed and standardised system of training and testing developed in collaboration with the Minnesota group, and during the survey there were frequent quality control checks. Each record was coded independently by two coders. If their verdict agreed it was accepted: in cases of disagreement one of us adjudicated.

The relation of individual electrocardiographic findings to coronary heart disease has been assessed in this study by looking for (1) a prevalence that rises with age; (2) an association with present or previous 'symptomatic heart disease', as suggested at the initial examination by either (a) a positive result to the chest pain questionnaire (angina or history of possible myocardial infarction) or (b) a report from the man that he was already under medical care for heart disease or blood pressure; and (3) an increased risk of death from coronary heart disease in the ensuing 5 years, measured by the ratio of observed to expected deaths. The latter was calculated by applying to the test group the agespecific coronary heart disease mortality rates for all men in the study.

\section{Results}

\section{PREVALENCE}

The prevalence rates for individual electrocardiographic findings are shown in Table 1. Certain items of the Minnesota Code have not been reported, either because of their rarity in working men (e.g. paroxysmal tachycardias), or because they were considered irrelevant (e.g. Code 9:4, which describes rotation of the heart). In the final column of Table 1 is shown the percentage of men in each

Table 1 Prevalence (numbers and rates per thousand) of electrocardiographic findings (limb leads only)

\begin{tabular}{|c|c|c|c|c|}
\hline \multirow[t]{2}{*}{ Electrocardiographic finding (and Minnesota Code) } & \multicolumn{3}{|c|}{ Numbers (and rates per 1000 ) } & \multirow{2}{*}{$\begin{array}{l}\text { Per cent with symptomatic history } \\
\text { (age-adjusted) }\end{array}$} \\
\hline & $40-49 y$ & $50-59 y$ & $60-64 y$ & \\
\hline $\begin{array}{l}\text { Q wave } \\
\text { Large }(1: 1) \\
\text { Medium }(1: 2) \\
\text { Small }(1: 3) \\
\text { Total }(1: 1-3)\end{array}$ & $\begin{array}{r}2(0.3) \\
27(3 \cdot 5) \\
86(11 \cdot 1) \\
115(14 \cdot 9)\end{array}$ & $\begin{array}{c}13(1 \cdot 6) \\
40(4 \cdot 8) \\
119(14 \cdot 4) \\
172(20 \cdot 8)\end{array}$ & $\begin{array}{l}13(5 \cdot 4) \\
29(12 \cdot 1) \\
33(13 \cdot 8) \\
75(31 \cdot 4)\end{array}$ & $\begin{array}{l}61 \\
35 \\
20 \\
27\end{array}$ \\
\hline $\begin{array}{l}\text { Axis deviation } \\
\text { Left }(2: 1) \\
\text { Right }(2: 2) \\
\text { Tall R wave }(3: 1) \\
\text { ST depression } \\
\text { Major }(4: 1) \\
\text { Intermediate }(4: 2) \\
\text { Minor }(4: 3) \\
\text { Upwards sloping }(4: 4) \\
\text { Total }(4: 1-4)\end{array}$ & $\begin{array}{l}10(1 \cdot 3) \\
18(2 \cdot 3) \\
16(2 \cdot 1) \\
11(1 \cdot 4) \\
55(7 \cdot 1)\end{array}$ & $\begin{array}{c}272(32 \cdot 8) \\
1(0 \cdot 1) \\
52(6 \cdot 3) \\
13(1 \cdot 6) \\
73(8 \cdot 8) \\
63(7 \cdot 6) \\
6(0 \cdot 7) \\
155(18 \cdot 7)\end{array}$ & $\begin{array}{c}119(49 \cdot 9) \\
0(0) \\
23(9 \cdot 6) \\
\\
5(2 \cdot 1) \\
32(13 \cdot 4) \\
23(9 \cdot 6) \\
3(1 \cdot 3) \\
63(26 \cdot 4)\end{array}$ & $\begin{array}{l}48 \\
50 \\
33 \\
27 \\
42\end{array}$ \\
\hline $\begin{array}{l}\text { T wave inversion } \\
\text { Major }(5: 1) \\
\text { Intermediate }(5: 2) \\
\text { Minor or flattening }(5: 3) \\
\text { Total }(5: 1-3)\end{array}$ & $\begin{array}{c}1(0 \cdot 1) \\
33(4 \cdot 3) \\
115(14 \cdot 9) \\
149(19 \cdot 3)\end{array}$ & $\begin{array}{c}2(0 \cdot 2) \\
110(13 \cdot 3) \\
338(40 \cdot 8) \\
450(54 \cdot 3)\end{array}$ & $\begin{array}{r}1(0 \cdot 4) \\
42(17 \cdot 6) \\
139(58 \cdot 2) \\
182(76 \cdot 2)\end{array}$ & $\begin{array}{l}65 \\
48 \\
21 \\
27\end{array}$ \\
\hline $\begin{array}{l}\text { AV conduction defect } \\
3^{\circ} \text { block }(6: 1) \\
2^{\circ} \text { block }(6: 2) \\
1^{\circ} \text { block }(6: 3) \\
\text { WPW syndrome }(6: 4) \\
\text { Accelerated }(6: 5)\end{array}$ & $\begin{aligned} 0 & (0) \\
1 & (0 \cdot 1) \\
144 & (18 \cdot 6) \\
2 & (0 \cdot 3) \\
36 & (4 \cdot 7)\end{aligned}$ & $\begin{array}{c}0(0) \\
1(0 \cdot 1) \\
215(26 \cdot 0) \\
2(0 \cdot 2) \\
31(3 \cdot 7)\end{array}$ & $\begin{array}{c}0(0) \\
1(0 \cdot 4) \\
81(33 \cdot 9) \\
0(0) \\
10(4 \cdot 2)\end{array}$ & $\begin{array}{r}-45 \\
16 \\
0 \\
13\end{array}$ \\
\hline $\begin{array}{l}\text { Ventricular conduction defect } \\
\text { Left BBB }(7: 1) \\
\text { Other }(7: 2,7: 4)\end{array}$ & $\begin{array}{l}76(9 \cdot 8) \\
39(5 \cdot 0)\end{array}$ & $\begin{aligned} 134 & (16 \cdot 2) \\
62 & (7 \cdot 5)\end{aligned}$ & $\begin{array}{l}76(31 \cdot 8) \\
27(11 \cdot 3)\end{array}$ & $\begin{array}{l}22 \\
19\end{array}$ \\
\hline $\begin{array}{l}\text { Rhythm and rate } \\
\text { Frequent premature beats }(8: 1) \\
\text { Atrial fibrillation }(8: 3) \\
\text { Rate }>100 / \min (8: 7) \\
\text { Rate }<50 / \text { min }(8: 8) \\
\text { Low QRS amplitude }(9: 1)\end{array}$ & $\begin{array}{c}65(8 \cdot 4) \\
12(1 \cdot 6) \\
198(25 \cdot 6) \\
107(13 \cdot 8) \\
56(7 \cdot 2)\end{array}$ & $\begin{array}{c}122(14 \cdot 7) \\
31(3 \cdot 7) \\
188(22 \cdot 7) \\
103(12 \cdot 4) \\
62(7 \cdot 5)\end{array}$ & $\begin{array}{l}62(26 \cdot 0) \\
27(11 \cdot 3) \\
51(21 \cdot 4) \\
35(14 \cdot 7) \\
25(10 \cdot 5)\end{array}$ & $\begin{array}{l}19 \\
57 \\
11 \\
12 \\
17\end{array}$ \\
\hline Study population & 7732 & 8284 & 2387 & $13 \cdot 2$ \\
\hline
\end{tabular}


electrocardiographic category is shown in whom there was evidence of symptomatic heart disease, as defined in the previous paragraph; this percentage was calculated after adjusting for the age distribution of the men in that particular electrocardiographic category. A few men with missing information were included in the non-symptomatic group. In the remaining men the survey electrocardiogram apparently provided the first indication of cardiovascular disease. Among the study population as a whole 13 per cent of men had 'symptomatic heart disease' (as defined), including 4 per cent currently under medical care. This value can be used to assess an excess frequency of symptoms observed in any particular electrocardiographic category.

$Q / Q S$ findings were coded in a total of 362 men (20 per 1000). Associations with age and with a symptomatic history were both clearly evident. Large $Q$ waves (Code 1:1) were rare, being recorded in only 28 cases; but the age gradient was very steep and over half of the affected men gave a symptomatic history. Two-thirds of codable Q/QS items fell into the class of small $Q$ waves (Minnesota Code 1:3); here the age gradient was shallow and only 20 per cent of the men gave a symptomatic history. For medium $Q$ waves (Code 1:2) the findings were intermediate.

Left axis deviation (Code 2:1) was one of the commonest items, with a rate overall of 31 per 1000 . An age gradient was clear, but there was little association with symptomatic history. The Minnesota Code criterion for right axis deviation is stringent $\left(+120^{\circ}\right.$ or more) and this was met in only 2 cases. The prevalence estimate for tall left ventricular $R$ waves (Code 3:1) was lowered by the omission of chest leads, but the finding was still common (7 per 1000 overall); however, it showed neither a consistent rise with age nor any large association with symptomatic history.

$S T$ depression items were uncommmon. Prevalence increased steeply with age, except for Code $4: 4$ (upwards-sloping segments). The proportion with a symptomatic history was high, ranging from 27 per cent for upwards-sloping segments up to around 50 per cent in the major and intermediate classes (Codes 4:1-2).

$T$ wave inversion or flattening was the commonest of all findings. It was strongly related to age, and also (except perhaps for the least grade, Code 5:3) to a symptomatic history.

First degree atrioventricular block (Code 6:3, PR $>0.22 \mathrm{~s}$ ) was also common, with a prevalence overall of 24 per 1000 men. Its prevalence increased steadily with age, but the association with symptomatic history as ascertained in this study was small and not statistically significant. There were 3 men with second degree $\mathrm{AV}$ block ( 1 of them with a symptomatic history), and 4 with Wolff-Parkinson- $c$ White syndrome (none of them with a known history). Complete AV block (Code 6:1) was notobserved. Accelerated AV conduction (Code 6:5) 흠 was seen in 77 men; but it seemed not to be asso- $\frac{\bar{F}}{\bar{T}}$ ciated with either age or symptomatic history.

Left bundle-branch block (Code 7:1) was seen in 286 men, the prevalence rising steeply with age. Though the number with a symptomatic history was. significantly above the chance expectation, it may be $\overrightarrow{\vec{\omega}}$ more relevant to stress that almost 80 per cent gave $\stackrel{\omega}{\omega}$ no history either of significant chest pain or of being under medical care. The omission of chest lead recordings made it necessary to group right bundlebranch block and intraventricular conduction defects $\delta$ together. However, even the combined group had a

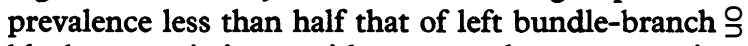
block; associations with age and symptomatic history were present, but not so strong.

Premature beats are recorded in the Minnesota Code only if they form at least 10 per cent of all $\overrightarrow{0}$ recorded beats; their prevalence, and associations with age and symptomatic history, were much the same as for left bundle-branch block. Atrial fibrillation was seen in 4 per 1000 men; there was a very steep age gradient, and over half gave some symptomatic history. Codable extremes of heart rate were $\frac{\circ}{\varnothing}$

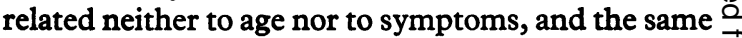
was true for low QRS amplitude.

\section{MORTALITY FOLLOW-UP}

Table 2 shows 5 -year coronary heart disease mortality results according to the initial electro- $\overparen{D}$ cardiographic findings (omitting right axis deviation $\frac{\varrho}{7}$ and complete atrioventricular block, because of $\dot{0}$ small numbers). Subjects have been divided ac- 3 . cording to whether or not at the time of screening $ᄋ$ they gave a symptomatic history, as previously $₹$ defined. Even with so large a study as this, numbers are small in some low-prevalence electrocardio- $D$ graphic categories and this must be borne in mind in interpreting the rates. The latter have been $N$ standardised, using the direct method, so that the outcome can be compared in groups which differed $N$ considerably in their age composition.

The most striking result is the difference in prognostic significance of specific electrocardio- 0 graphic findings according to the presence or $\mathbb{\Phi}$ absence of symptoms. In the group with no sympto- + matic history, with the exception of prominent $\frac{T}{0}$ $Q$ waves (Codes 1:1-2) and atrial fibrillation, there $\frac{O}{\mathbb{D}}$ is no other electrocardiographic category where the $\stackrel{\odot}{\odot}$ 5 -year coronary heart disease mortality rate achieves $\stackrel{\AA}{\Omega}$ a figure of even 5 per cent. Among these other $\bar{\gamma}$ categories the excess mortality reaches the 5 per cent $\delta$ 
Table 2 Five-year coronary heart disease mortality (numbers and age-adjusted rates) according to initial electrocardiographic findings and presence or absence of symptomatic history

\begin{tabular}{|c|c|c|c|}
\hline \multirow{2}{*}{$\begin{array}{l}\text { Electrocardiographic } \\
\text { finding (and Minnesota } \\
\text { Code) }\end{array}$} & \multicolumn{2}{|c|}{$\begin{array}{l}\text { No. (and age-adjusted } \\
\text { rate } \%)^{\star}\end{array}$} & \multirow{2}{*}{$\begin{array}{l}\text { Total: } \\
\text { age-adjusted } \\
\text { rate } \% \star\end{array}$} \\
\hline & $\begin{array}{l}\text { Non- } \\
\text { symptomatic }\end{array}$ & Symptomatic & \\
\hline $\begin{array}{l}\text { Q wave } \\
\text { Large }(1: 1) \\
\text { Medium }(1: 2) \\
\text { Small }(1: 3) \\
\text { Total }(1: 1-3)\end{array}$ & $\begin{array}{l}7(42) \\
58(5) \\
189(3) \\
254(4)\end{array}$ & $\begin{array}{c}21(7) \\
38(9) \\
49(9) \\
108(9)\end{array}$ & $\begin{array}{r}25 \cdot 5 \\
7 \cdot 8 \\
4 \cdot 8 \\
6 \cdot 1\end{array}$ \\
\hline $\begin{array}{l}\text { Left axis deviation }(2: 1) \\
\text { Tall } R \text { wave }(3: 1) \\
\text { ST depression } \\
\text { Major }(4: 1) \\
\text { Intermediate }(4: 2) \\
\text { Minor }(4: 3) \\
\text { Upwards-sloping }(4: 4) \\
\text { Total }(4: 1-4)\end{array}$ & $\begin{array}{l}14(0) \\
59(2) \\
58(3) \\
15(0) \\
146(2)\end{array}$ & $\begin{array}{r}14(39) \\
64(11) \\
44(11) \\
5(0) \\
127(17)\end{array}$ & $\begin{array}{r}17 \cdot 9 \\
7 \cdot 0 \\
6.5 \\
0.0 \\
8 \cdot 2\end{array}$ \\
\hline $\begin{array}{l}\text { T wave inversion } \\
\text { Major }(5: 1) \\
\text { Intermediate }(5: 2) \\
\text { Minor or flattening }(5: 3) \\
\text { Total }(5: 1-3)\end{array}$ & $\begin{array}{r}2(0) \\
82(3) \\
446(3) \\
530(3)\end{array}$ & $\begin{array}{l}2(0) \\
103(21) \\
146(8) \\
251(13)\end{array}$ & $\begin{array}{r}0 \cdot 0 \\
11 \cdot 2 \\
4 \cdot 6 \\
5 \cdot 8\end{array}$ \\
\hline $\begin{array}{l}\text { AV conduction defect } \\
2^{\circ} \text { block }(6: 2) \\
1^{\circ} \text { block }(6: 3) \\
\text { WPW syndrome }(6: 4) \\
\text { Accelerated conduction } \\
(6: 5)\end{array}$ & $\begin{array}{r}2(0) \\
366(1) \\
4(0)\end{array}$ & $\begin{array}{c}1(45) \\
74(4) \\
0(-)\end{array}$ & $\begin{array}{r}45 \cdot 0 \\
1 \cdot 5 \\
0 \cdot 0\end{array}$ \\
\hline $\begin{array}{l}\text { Ventricular conduction defec } \\
\text { Left BBB }(7: 1)\end{array}$ & 219 & $67(8)$ & $4 \cdot 7$ \\
\hline \multicolumn{4}{|l|}{ Rhythm and rate } \\
\hline $\begin{array}{l}\text { Frequent premature beats } \\
(8: 1) \\
\text { Atrial fibrillation }(8: 3) \\
\text { Rate }>100 / \min (8: 4) \\
\text { Rate }<50 / \min (8: 8) \\
\text { Low QRS amplitude }(9: 1)\end{array}$ & $\begin{array}{c}200(3) \\
33(7) \\
388(1) \\
216(0) \\
118(0)\end{array}$ & $\begin{array}{l}49(4) \\
37(3) \\
49(12) \\
29(7) \\
25(8)\end{array}$ & $\begin{array}{l}3 \cdot 3 \\
4 \cdot 8 \\
2 \cdot 2 \\
0 \cdot 8 \\
2 \cdot 2\end{array}$ \\
\hline Study population & 15974 (1) & $2429(5)$ & 1.5 \\
\hline
\end{tabular}

*Italics indicate that rate is not significantly different, at 5 per cent level, from that in men without this finding.

ievel of statistical significance only for small $Q$ waves (Code 1:3), left axis deviation, flattened or slightly inverted $T$ waves (Code 5:3), and left bundle-branch block. The dominant impression throughout this non-symptomatic group is the lowness of the risk. During the 5-year follow-up period, among 462 men with left axis deviation, only 2 per cent died of coronary heart disease; and among 321 with ventricular conduction defects, again only 2 per cent died. Among 366 men with prolonged PR interval $(>0.22 \mathrm{~s})$ the coronary heart disease mortality rate was actually slightly lower than among the study group as a whole, though the difference was within chance limits.

In the group with a symptomatic history the prognostic significance of the electrocardiographic findings was generally more serious: the increased mortality achieved statistical significance in addition for ST depressions (unless upwards-sloping), intermediate $T$ wave inversions (Code 5:2), and sinus tachycardia.

In neither the symptom-positive nor the symptom-negative group was there any significant or important increase in risk for increased $R$ amplitude, junctional ST depression with upwardssloping segment, delayed or accelerated AV conduction, frequent premature beats, sinus bradycardia, or low QRS amplitude.

The association of a particular electrocardiographic finding with a poor prognosis may mean either that it is independently predictive in its own right or merely that it is sometimes associated with true predictors. We, therefore, analysed further those items in Table 2 which were associated with a doubling or more of the coronary heart disease mortality rate, in order to assess their predictive power in those cases where only one item from this group had been coded. Table 3 sets out the main findings; mortality ratios have been calculated by dividing the age-adjusted rate in each category by the rate for the whole study group. (No results are given for ST depressions, codes 4:1-3: according to the Minnesota Code these cannot be present as isolated findings, but require in addition a $\mathrm{T}$ wave code.) In general the estimated risks are now less, but the changes are not large.

Fig. 1 illustrates the contrasting significance of particular findings according to the context in which

Table 3 Findings associated with increased coronary heart disease mortality: prognosis for (a) all cases, and (b) cases where no other item from this group was present

\begin{tabular}{|c|c|c|}
\hline \multirow[t]{2}{*}{ Electrocardiographic findings } & \multicolumn{2}{|c|}{$\begin{array}{l}\text { No. ( + age-adjusted } \\
\text { coronary heart disease } \\
\text { mortality ratio) }\end{array}$} \\
\hline & All cases & $\begin{array}{l}\text { Specified item } \\
\text { only }\end{array}$ \\
\hline \multicolumn{3}{|l|}{ Q wave } \\
\hline Large $(1: 1)$ & $28(16.9)$ & $6(27 \cdot 9)$ \\
\hline Medium $(1: 2)$ & $96(5 \cdot 2)$ & $67(4 \cdot 1)$ \\
\hline Small $(1: 3)$ & $238(3 \cdot 2)$ & $158(2 \cdot 1)$ \\
\hline Left axis deviation (2:1) & $569(2 \cdot 3)$ & $465(1 \cdot 6)$ \\
\hline \multicolumn{3}{|l|}{$T$ wave inversion } \\
\hline Intermediate $(5: 2)$ & $185(7 \cdot 4)$ & $20(2 \cdot 7)$ \\
\hline Minor or flattening $(5: 3)$ & $592(3.0)$ & $391(2 \cdot 5)$ \\
\hline $\begin{array}{l}\text { AV conduction defect } \\
2^{\circ} \text { block }(6: 2)\end{array}$ & $3(29.9)$ & $2(0.0)$ \\
\hline \multicolumn{3}{|l|}{ Ventricular conduction defects } \\
\hline $\begin{array}{l}\text { Left BBB }(7: 1) \\
\text { Other }(7: 2,7: 4)\end{array}$ & $\begin{array}{l}286(3 \cdot 1) \\
128(2 \cdot 2)\end{array}$ & $\begin{array}{l}273(3 \cdot 1) \\
104(1 \cdot 7)\end{array}$ \\
\hline \multicolumn{3}{|l|}{ Rhythm and rate } \\
\hline $\begin{array}{l}\text { Frequent premature beats }(8: 1) \\
\text { Atrial fibrillation }(8: 3)\end{array}$ & $\begin{array}{r}249(2 \cdot 2) \\
70(3 \cdot 2)\end{array}$ & $\begin{array}{r}198(1 \cdot 7) \\
47(3 \cdot 5)\end{array}$ \\
\hline
\end{tabular}




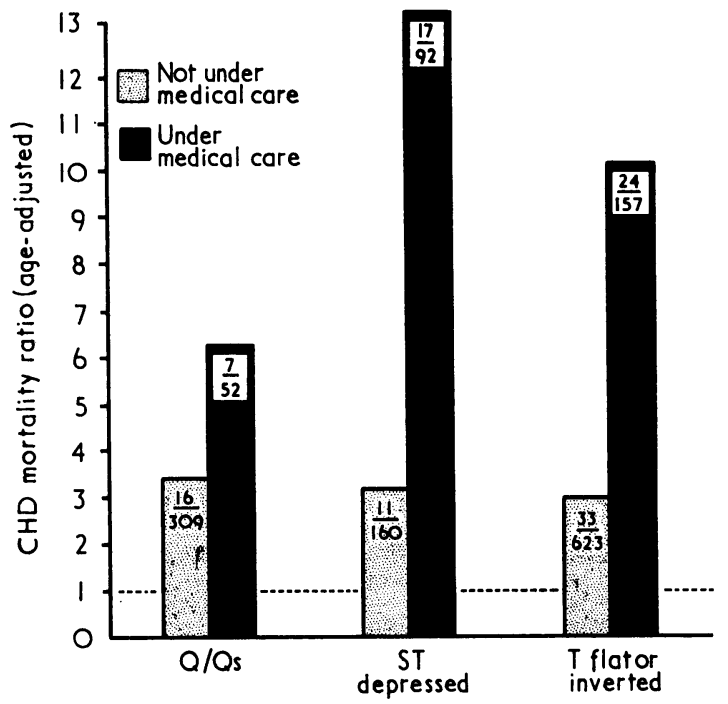

Fig. 1 Prognosis of ischaemic-type electrocardiographic findings according to whether men were under medical care. $(Q / Q S=$ Codes $1: 1-3, S T$ depressed $=$ Codes $4: 1-4, T$ flat or inverted $=$ Codes $5: 1-3$.)

they occur. As seen by the doctor providing medical care, the prognosis for each of the main classes of electrocardiographic abnormality is two to four times worse than for those subjects where the same abnormality was first discovered by screening.

Fig. 2 analyses the overlap between the predictive information derived from various sources. Where the evidence of myocardial ischaemia (as defined in the figure legend) came only from the electrocardiogram or the chest pain questionnaire the 5-year coronary heart disease mortality, though significantly increased, was still only around 3 per cent; this compared with 1.5 per cent for the whole study group. The highest mortality rate $(20 \%)$ occurred in men who were under care and who were additionally positive to both the electrocardiogram and the chest pain questionnaire; only 107 men were in this category, which thus contributed only 20 of the total coronary heart disease deaths $(7 \%)$.

\section{Items not identified by the Minnesota Code}

\section{DETAILS OF VENTRICULAR PREMATURE BEATS}

The Minnesota Code does not take note of premature beats unless they form 10 per cent or more of recorded complexes, nor does it distinguish them according to their origin. This crude classification gave a 5-year coronary heart disease mortality ratio of $2 \cdot 2$ but this was not significantly above unity. In order to provide a better test, a review was under- taken of the electrocardiograms of 165 men who had died of coronary heart disease during the 5-year $\stackrel{c}{.}$ follow-up period and in whom at the initial examina- $\overrightarrow{\vec{F}}$ tion the electrocardiogram showed no codable -0 $\mathrm{Q} / \mathrm{QS}, \mathrm{ST}$, or T items or left bundle-branch block and the response to the chest pain questionnaire was $\frac{\overline{\bar{N}}}{\bar{a}}$ negative. (In order to increase the numbers, this $\stackrel{\varnothing}{\varnothing}$ sample included 25 men aged 65 and above.) For each man an age-matched control was selected at ${ }^{\mathrm{C}}$ random from among the survivors meeting the same. criteria. The results for ventricular premature beats $\overrightarrow{\vec{\omega}}$ (any number) are shown in Table 4. Among the ${ }^{\omega}$ men who subsequently died of coronary heart disease, ventricular premature beats were present in $\vec{f}$ only 4 per cent, negligibly more than in the controls. There were no instances of multifocal or complicated beats.

Table 4 Prevalence of finding ventricular premature beats (any number) at initial examination (a) in men dying of coronary heart disease in next 5 years, (b) in random sample of men surviving this period

\begin{tabular}{lrlll}
\hline \multirow{2}{*}{ Age (y) } & \multicolumn{2}{c}{ (a) Deaths } & \multicolumn{2}{c}{ (b) Controls } \\
& Total & No. with VPBs & Total & No. with VPBs \\
\hline $40-49$ & 21 & $2(10 \%)$ & 21 & $1(5 \%)$ \\
$50-59$ & 79 & $2(2 \%)$ & 79 & $1(1 \%)$ \\
$60+$ & 65 & $3(5 \%)$ & 65 & $3(5 \%)$ \\
$\begin{array}{l}\text { Total (and age- } \\
\text { adjusted \%) }\end{array}$ & & $7(65 \%)$ & 165 & $5(3 \%)$ \\
\hline
\end{tabular}

VPB, ventricular premature beat.

\section{QT INTERVAL}

Drugs which prolong the QT interval tend also to lower the threshold for ventricular fibrillation. This? raises the possibility that even in the absence of $\frac{}{3}$ drug therapy the QT interval might itself influence ${ }_{-}^{-}$. the threshold for fatal arrhythmias. This hypothesis was tested by analysing the distribution of $\mathrm{QT}$ intervals in this same group of 165 men, initially free $\frac{}{-}$ of evident disease, who subsequently died of coronary heart disease and comparing it with the findings in the age-matched control group. N

An appropriate correction for heart rate was $_{N}$ considered to be particularly important in view of possible differences in rates between the decedents ${ }^{\omega}$ and the survivors. As the other results from thise study have emphasised, the significance of electro- - ? cardiographic findings in the general population may not be the same as that observed in clinical practice. For this reason it was thought unwise to use the conventional tables for QT interval correc-需 tion, and preferable to apply a correction based on the relation between QT interval and heart rate in our own data. Preliminary inspection disclosed the expected strong correlation, with no significant 


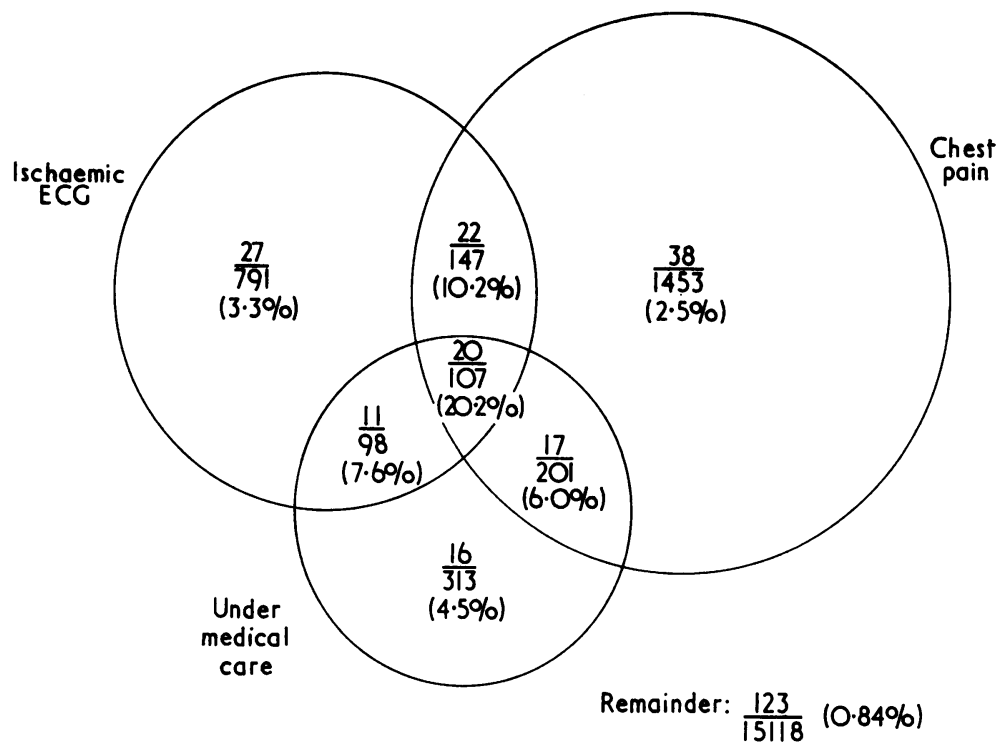

Fig. 2 Five-year coronary heart disease mortality (age adjusted $\%$ ) according to source of information on possible heart disease, for 18228 men with complete data. (Chest pain $=$ positive to 'angina of effort' and I or 'possible infarction' sections of questionnaire. Ischaemic electrocardiogram $=$ any codable $Q / Q S$ items, Codes 1:1-3; ST depression, Codes $4: 1-4 ; T$ wave inversion or flattening, Codes 5:1-3; or left bundle-branch block, Code 7:1.)

departure from a linear relation. A fitted linear regression gave the following function

$$
\text { QT }(\mathrm{s})=0.053+0.0107 \mathrm{RR}(\mathrm{mm}) \text {. }
$$

The slope of this regression was used to correct each observed $R R$ interval to the value predicted for a rate of $60 / \mathrm{min}$. The mean $\mathrm{QT}_{\mathrm{c}}$ for the decedents then proved to be $0.411 \mathrm{~s}$ and for the controls $0.412 \mathrm{~s}$-an unarguably negative finding.

\section{Discussion}

The results of an epidemiological inquiry can be generalised only to the extent that the study group can be considered representative. The 5-year coronary heart disease mortality rate for the whole study group was 15 per 1000 , compared with an expectation of 25 per 1000 based on the agespecific rates for England and Wales in the mid-year of the follow-up period. The London civil servants in this study were certainly selected regionally and socioeconomically, though all employment grades were included in the study. Medical selection was probably less important, since entry did not depend on a medical examination. Selective retirement certainly occurred, but excluding all men over the age of 60 did not alter any of the main conclusions. The excellent service provided by the NHS Central Register, which was 99 per cent complete, ruled out the possibility of bias in the mortality follow-up.

In epidemiological studies the electrocardiogram provides one of the most important indicators of atherosclerotic disease. With the possible exception of large $Q$ waves no pattern is completely specific for ischaemia; the same findings may result from other myocardial diseases, or perhaps simply from the extremes of physiological variation. This is well illustrated by the problem of ST segment depression. On the one hand this may betoken ischaemic injury; but recent work has shown (Taggart et al., 1977) that indistinguishable patterns may sometimes appear in apparently healthy men during infusion of catecholamines, or at periods of emotional stress. Coronary angiography in such cases has shown unobstructed arteries, and obviously the prognosis is likely to be very different from that of frank myocardial ischaemia. For surveys and intervention studies it is necessary to know which patterns are sufficiently specific to be used as end-points for coronary heart disease. This cannot usually be established from clinical studies, since it depends on the relative frequencies in the particular study group of myocardial ischaemia, other causes of myocardial injury, and physiologically deviant individuals: these relative frequencies may be quite different in hospital and in general populations. One of the aims of the present inquiry was to help establish for population studies the specific electrocardiographic findings which can be used to identify coronary heart disease.

In addition, clinicians are increasingly required to interpret electrocardiograms taken for routine reasons rather than for particular symptomatic indications. Occupational medicine departments, general practitioners, and others may nowadays use the electrocardiogram as a screening rather than as a 
diagnostic tool, either for prognostic purposes or else as a guide to the need for remedial action. From Fig. 2 it can be seen that the combination of electrocardiography with a chest pain questionnaire identified 14 per cent of men as having suspected myocardial ischaemia, and in the next 5 years half of all the coronary deaths occurred among the men in this category; moreover, even at this stage of early ischaemia the main 'primary' risk factors still exert a major influence on prognosis (Rose et al., 1977b). This adds some weight to the possible value of the electrocardiogram as part of a screening and preventive service. Conclusions on this important point should, however, await some direct evidence on the benefits of intervention, though in the meantime it may again be helpful to identify the specific electrocardiographic findings that are associated with an increased risk of coronary death.

The present study set out to discover evidence linking particular electrocardiographic findings with the presence of coronary heart disease on the basis of (1) a prevalence rate that rises with age, (2) an association with a symptomatic history, and (3) an increased risk of subsequent coronary mortality. Codable $\mathrm{Q} / \mathrm{QS}$ findings met all three criteria, but to a diminishing degree as their size diminished: for the least $\mathrm{Q} / \mathrm{QS}$ grade (Code 1:3) and in the absence of symptoms, the 5-year survival rate was over 95 per cent. Even for symptomatic men with large $Q$ waves, more than 90 per cent survived this period.

Other findings where these criteria indicated a clear association with coronary heart disease were ventricular conduction defects, ST depressions (except for junctional depression with upwardssloping segment), and even minor $\mathrm{T}$ wave inversion or flattening, the latter category being predictive even when it was the only recorded abnormality. In this respect our findings differ from the Framingham Study, where minor $T$ wave inversion or flattening carried no significant risk when present as an isolated finding (Higgins et al., 1965). Sinus bradycardia (rate $<50 / \mathrm{min}$ ) and accelerated atrioventricular conduction had no apparent prognostic significance. Four instances of Wolff-ParkinsonWhite syndrome were seen; all were apparently symptomless and all survived. Like Blackburn et al. (1970), we found that tall left ventricular $R$-waves had little significance. But in contrast with their findings from the Seven Countries Study we found greater prognostic significance for small $Q$ waves and left axis deviation, and less for first degree atrioventricular block and premature beats. Our negative experience in regard to the latter differs also from that of life insurance companies (e.g., Lyle, 1964). Even for those items that were clearly associated with coronary heart disease, the risk in absolute terms tended to be much lower than in the $c$. American studies. For example, in the Framingham $\overrightarrow{\vec{F}}$ Study (Kannel et al., 1969) 'left ventricular hyper- $\overrightarrow{0}$ trophy' in men aged 45 to 62 carried an estimated $\frac{}{5}$ 4-year mortality of 30 per cent, a risk not equalled in $\overline{\frac{\bar{s}}{4}}$ our study even for major $Q$ waves.

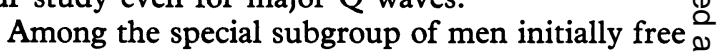
of evidence of ischaemia, neither $\mathrm{QT}_{\mathrm{c}}$ nor ven- ${ }^{\infty}$ tricular premature beats bore any relation to $\vec{\circ}$ prognosis.

Perhaps the most striking finding to emerge from ${ }_{\sigma}$ population studies of the electrocardiogram is the large difference in prognosis according to the reason for which the record was taken in the first place. For example, 1-year mortality rates of 50 per cent os and more have been reported for left bundle-branch $\mathscr{\omega}$ block occurring in hospital patients with acute $\frac{\text { 의 }}{2}$ myocardial infarction; but of the 286 men in whom it was seen in the present study only $17(5 \%)$ died $c$ of coronary heart disease in the next 5 years. Even $\underset{\widehat{\Phi}}{\overrightarrow{0}}$ within the study there were big differences in $\vec{\oplus}$ prognosis between symptomatic and non-symptomatic men. For example, moderate $T$ wave inversion (Code $5: 2$ ) occurred in 103 men with a symptomatic history, of whom 21 per cent died; but among 82 symptomless men with an indistinguishable electrocardiographic pattern, only $\frac{\otimes}{\varnothing}$ 3 per cent died during the next five years. The con- $\bigcirc$ trasting prognosis of seemingly identical electro- $\overrightarrow{\overrightarrow{0}}$ cardiograms was further brought out in Fig. 1, 3 where it was shown that for men under medical care the mortality rate within defined electrocardiographic categories was up to four times worse than $\vec{\partial}$ for those men not currently under care. Though one should not dismiss the possibility that medical $\frac{0}{0}$ treatment can sometimes have an adverse effect on 3 outcome, at least the main explanation of this $\delta$ phenomenon must be that men who go to see the $₹$ doctor tend to be worse cases than those who stay 음 away.

Doctors are increasingly being confronted by all kinds of medical information which do not arise out of any relevant complaint by the patient. Many \% are unaware that the diagnostic significance and $\tilde{O}$ prognosis of signs arising in the general population $N$ can be very different from those of the identicalo findings arising in the course of clinical practice, 0 and in the case of electrocardiography in particular $\mathbb{D}$ this can cause the patient much unnecessary alarm.? In the present study electrocardiographic $a b-\frac{T}{0}$ normalities suggestive of ischaemia, which were

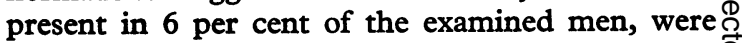
found to carry a subsequent mortality from coronary $\stackrel{\mathbb{Q}}{\Omega}$ heart disease averaging little more than 1 per cent a year. Compared with the rate in men whose electro-

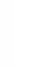


cardiograms were negative $(0 \cdot 2 \%)$ this was a highly significant excess, but to the individuals concerned the short-term risk was very small.

We thank the Civil Service for their collaboration in this study; our colleagues who coded the electrocardiograms; and Miss N. Robinson, $\mathrm{PhD}$., for the QT interval analysis.

\section{References}

Blackburn, H., Taylor, H. L., and Keys, A. (1970). The electrocardiogram in prediction of five-year coronary heart disease incidence among men aged 40 through 59. Circulation, 41, Suppl. 1, 154-161.

Caird, F. I., Campbell, A., and Jackson, T. F. M. (1974). Significance of abnormalities of electrocardiogram in old people. British Heart fournal, 36, 1012-1018.

Campbell, A., Caird, F. I., and Jackson, T. F. M. (1974). Prevalence of abnormalities of electrocardiogram in old people. British Heart fournal, 36, 1005-1011.

Evans, J. G., and Tunbridge, W. M. G. (1976). Information loss in limb-lead electrocardiograms compared with twelve-lead tracings in a population survey among the elderly. Age and Ageing, 5, 56-61.

Higgins, I. T. T., Kannel, W. B., and Dawber, T. R. (1965). The electrocardiogram in epidemiological studies. Reproducibility, validity, and international comparison. British fournal of Preventive and Social Medicine, 19, 53-68.
Kannel, W. B., Gordon, T., and Offutt, D. (1969). Left ventricular hypertrophy by electrocardiogram. Annals of Internal Medicine, 71, 89-105.

Lyle, A. M. (1964). Coronary disease as an underwriting problem. Transactions of the Society of Actuaries, 15, 324-350.

Reid, D. D., Brett, G. Z., Hamilton, P. J. S., Jarrett, R. J., Keen, H., and Rose, G. (1974). Cardiorespiratory disease and diabetes among middle-aged male civil servants. Lancet, 1, 469-474.

Rose, G. (1965). The coding of survey electrocardiograms by technicians. British Heart fournal, 27, 595-598.

Rose, G., and Blackburn, H. (1968). Cardiovascular Survey Methods. World Health Organization Monograph Series No. 56. World Health Organization, Geneva.

Rose, G., McCartney, P., and Reid, D. D. (1977a). Selfadministration of a questionnaire on chest pain and intermittent claudication. British fournal of Preventive and Social Medicine, 31, 42-53.

Rose, G., Reid, D. D., Hamilton, P. J. S., McCartney, P., Keen, H., and Jarrett, R. J. (1977b). Myocardial ischaemia, risk factors and death from coronary heart-disease. Lancet, 2, 105-109.

Taggart, P., Carruthers, M., Joseph, S., Kelly, B., Marcomichelakis, J., Nobel, D., O'Neill, G., and Somerville, W. (1977). Electrocardiographic changes resembling myocardial ischaemia in asymptomatic men with normal coronary arteriogram (abstract). British Heart fournal, 39, 346.

Requests for reprints to Professor Geoffrey Rose, London School of Hygiene and Tropical Medicine, Keppel Street, London WC1. 